Applying Trained Skills on the Job: The Importance of the Work Environment

\author{
J. Bruce Tracey* \\ School of Hotel Administration \\ Cornell University \\ 544 Statler Hall \\ Ithaca, NY 14853 \\ Scott I. Tannenbaum \\ School of Business \\ State University of New York at Albany \\ Business Administration 342 \\ 1400 Washington Avenue \\ Albany NY 12222 \\ Michael J. Kavanagh \\ School of Business \\ State University of New York at Albany \\ Business Administration 342 \\ 1400 Washington Avenue \\ Albany NY 12222
}

Published in Journal of Applied Psychology (1995), Vol. 80, No. 2, 239-252

${ }^{*}$ Corresponding author. Electronic mail may be sent via Internet to tracey@wpsmtp.sha.cornell.edu.

Author note: We are grateful to George Alliger, John Mathieu, Linda Stoddard, Paul Thayer, and Gary Yukl for their insights and valuable assistance in completing this research. A draft of this article was presented at the annual conference of the Society for Industrial and Organizational Psychology, San Francisco, May 1993. 


\begin{abstract}
The influence of the work environment on the transfer of newly trained supervisory skills was examined. Participants were 505 supermarket managers from 52 stores. The work environment was operationalized in terms of transfer of training climate and continuouslearning culture. Climate and culture were hypothesized to have both direct and moderating effects on posttraining behaviors. Accounting for pretraining behaviors and knowledge gained in training, the results from a series of LISREL analyses showed that both climate and culture were directly related to posttraining behaviors. In particular, the social support system appeared to play a central role in the transfer of training. Moderating effects were not found. Implications for enhancing the transfer of training are discussed.
\end{abstract}


Applying Trained Skills on the Job: The Importance of the Work Environment

One of the key criteria for evaluating the effectiveness of any formal training program is the transfer of training to the job (Kirkpatrick, 1967). Transfer of training may be defined as the degree to which trainees apply the knowledge, skills, behaviors, and attitudes gained in training to their jobs (Wexley \& Latham, 1991). This definition suggests that transfer of training is a function of factors within the formal training context as well as characteristics in the transfer or work environment.

Yet most of the research on training effectiveness has focused on factors within the formal training context, such as the design and content of training (Noe, 1986). Moreover, most evaluation efforts have concentrated on reaction and learning measures, two criteria that are collected within the training context (Alliger \& Janak, 1989; Saari, Johnson, McLaughlin, \& Zimmerte, 1988).

Significantly less research has examined the transfer of trained skills to the job, and even fewer studies have examined how the work environment influences such transfer (see Baldwin \& Ford, 1988). This is unfortunate. Research that examines the influence of the work environment on posttraining behaviors is valuable because it can help to move beyond the question of "whether training works" toward a better understanding of "why training works" (Campbell, 1988; Tannenbaum \& Yukl, 1992). This type of research has both theoretical and practical implications. From a theoretical standpoint, a more comprehensive conceptual framework of training effectiveness can be developed and tested by considering factors outside the formal training context. 
From a practical standpoint, research-guided enhancements to the work environment should result in increased training effectiveness and utility.

Despite the potential importance of the work environment, very little research has been conducted to identify, operationalize, and empirically assess training-specific situational factors that either facilitate or inhibit the application of newly acquired skills. This study attempts to address a limitation in the current literature by examining the influence of the work environment on the transfer of training.

\section{Transfer of Training}

Two recent reviews of the training literature highlighted the importance of the work environment for the transfer of training (Baldwin \& Ford, 1988; Tannenbaum \& Yukl, 1992). Baldwin and Ford argued that supervisory support and organizational climate are key variables that may influence the transfer process. Tannenbaum and Yukl stated that "elements of the posttraining environment can encourage (e.g., rewards, job aids), discourage (e.g., ridicule from peers), or actually prohibit the application of new skills and knowledge on the job (e.g., lack of necessary equipment)" (p. 420).

There has been some recent empirical evidence that supports the importance of the work environment. For example, Baldwin and Magjuka (1991) demonstrated that three organizational "signals" influence trainees' intentions to apply what they have learned to their jobs. They found that (a) when trainees received relevant information before the training program, (b) recognized that they would be held accountable for 
learning, and (c) perceived training as mandatory, trainees reported greater intentions to transfer learning back to their jobs. Ford, Quinones, Sego, and Sorra (1992) showed that trainees who perform similar jobs may experience significantly different opportunities to apply recently trained skills on the job. Thus, for some trainees, their work environment limits their ability to transfer what they learned. Moreover, these trainees will probably exhibit greater skill decay than those who get a greater chance to practice what they learned (Pentland, 1989).

The studies cited above have increased awareness of the importance of the environment. However, additional research is needed for a clear understanding of the influence of the work context on the application of trained skills. The few empirical studies in this area suggest that, collectively, several factors associated with the work environment may represent a training-specific dimension of organizational climate or culture that may be an important determinant of transfer. Therefore, in our study we examine the influence of the work environment in terms of training-specific organizational climate and continuous learning culture.

\section{Organizational Climate: Transfer of Training Climate}

There is some agreement that organizational climate can be conceptualized as individual perceptions about salient characteristics of the organizational context (Schneider, 1990). Many researchers have argued that organizational climate is based on the interaction between observable, objective elements of the organizational setting and the perceptual processes of organizational members (Hellreigel \& Slocum, 1974; 
James \& Jones, 1974, 1976; Schneider 1983a, 1983b). As organizational members pay attention to salient organizational characteristics, such as policies, reward systems, and managerial behaviors, they attach meaning to those characteristics on the basis of their personal values, beliefs, needs, and other individual characteristics. Thus, climate corresponds to the shared pattern of meanings among individuals about the major characteristics of an organizational context.

More recently, James and his colleagues have argued that climate may be distinguished in terms of psychological climate and organizational climate. James, James, and Ashe (1990) defined psychological climate as the "product of an interaction between information sensed from the environment and higher-order schemas engendered by latent personal values. The frame of reference for the products of this interaction —-the acquired meanings or valuations of environmental attributes—is ... the individual" (pp. 69-70). However, when individuals share similar perceptions about salient organizational attributes, then organizational climate is said to exist.

Most of the research that has examined the relationship between a broad notion of organizational climate and specific behavioral dependent variables has not found significant results (e.g., Pritchard \& Karasick, 1973). In contrast, studies that have examined specific dimensions of climate, such as technical updating climate (Kozlowski \& Hults, 1987) and safety climate (Zohar, 1980), have explained a significant proportion of variance in specific behavior-related variables. For example, Kozlowski and Hults (1987) found that perceptions about an organization's technical updating climate, which referred to perceptions about innovative behavior, updating activities, and job 
performance, were positively related to a number of important behavioral outcomes, such as the number of hours spent in training and problem-solving performance.

Focusing on specific dimensions of the overall organizational climate construct is consistent with the work of Schneider (1985), who argued that climate should be considered as a broad, multidimensional perceptual domain, with construct definition influenced by the specific criterion of interest. This suggests that a focused conceptualization of training climate may be necessary for understanding posttraining behavior.

This approach was taken by Rouiller and Goldstein (1993) when they conducted perhaps the only empirical study to assess the relationship between climate and a specific, training-related dependent variable: posttraining behaviors. They examined the "transfer of training climate," which was defined as "those situations and consequences which either inhibit or help to facilitate the transfer of what has been learned in training into the job situation" (p. 379).

On the basis of a review of the training literature, critical incidents collected from human resources personnel, and the behavior modification model developed by Luthans and Kreitner (1985), Rouiller and Goldstein (1993) proposed that a positive transfer climate consists of eight dimensions: goal cues, social cues, task and structural cues, self-control cues, positive feedback, negative feedback, punishment, and no feedback. These cues and consequences provide reminders for trainees to use their training once they return to their jobs. For example, so cial cues are the interactions among trainees, peers, and supervisors that prompt trainees to apply their training to 
their jobs. The more positive the interactions, the more likely that trainees will demonstrate trained behaviors and skills.

Rouiller and Goldstein (1993) collected data from 102 manager trainees (i.e., new managers) and their supervisors as well as 297 coworkers in 102 restaurants from a large chain of fast-food franchises. The procedure was as follows: Transfer of training climate surveys were collected from at least two managerial coworkers from each of the 102 restaurants. Next, the manager trainees attended a mandatory training program on basic managerial skills and behaviors that focused on topics such as employee relations, food preparation and handling, shift management, and customer service. Learning measures were collected from the trainees during the training program. Finally, surveys evaluating the manager trainees' use of trained behaviors were collected from managers and subordinates several weeks after the arrival of the new trainee manager.

Their results showed that aggregated perceptions of transfer climate (i.e., unit level) were related to posttraining behaviors, after accounting for learning in training and unit performance. Two general dimensions of transfer climate, situational cues and consequences, each explained unique variance in posttraining behaviors. Thus, climate expressed in training-specific terms was found to be important for the transfer of training back to the job.

Rouiller and Goldstein's (1993) study provides new insights into the influence of training climate, but some questions remain. First, at what level does training climate operate? They considered climate at the unit (i.e., restaurant) level. However, climate may operate at the individual or psychological level, or it may be a shared perception at 
the group or unit level. Second, does training climate have the same effect on experienced trainees as it does on new employees? Rouiller and Goldstein examined trainees entering a new work environment. Yet, experienced employees often attend training and then return to work, so it is important to know if they are similarly affected by training climate. Third, are there other important factors associated with the work environment, not examined by Rouiller and Goldstein, that may influence transfer of training? One potential factor is continuous-learning culture.

\section{Organizational Culture: Continuous-Learning Culture}

Several authors have suggested that a continuous- learning work environment may be an important construct for understanding the application of trained behaviors (Dubin, 1990; Noe \& Ford, 1992; Rosow \& Zager, 1988). Although a cogent and clear definition of a continuous-learning work environment has not yet been presented in the literature, it has been discussed in terms of several individual, task, and organizational characteristics. First, a continuous-learning work environment is one in which knowledge and skill acquisition are essential responsibilities of every employee's job (Rosow \& Zager, 1988). Job assignments are challenging and are designed to promote personal development (Dubin, 1990). Moreover, learning becomes a taken-for-granted part of every job in an organization, and this tacit understanding is embedded within the framework of organizational meaning (Schein, 1985).

Second, a continuous-learning work environment is one in which knowledge and skill acquisition are supported by social interaction and work relationships (Dubin, 
1990). By working together in a highly interactive work context, organizational members gain an understanding of each others' tasks and responsibilities and clearly recognize the interrelationships among jobs. Cooperation and cohesion among employees, managers, teams, functional units, and so on, are encouraged and supported such that they become institutionalized (Kozlowski \& Hults, 1987; Rosow \& Zager, 1988).

Third, organizations that have a continuous-learning work environment have developed formal systems that reinforce achievement and provide opportunities for personal development (Dubin, 1990). Organizational members are provided with resources and opportunities necessary to acquire and apply new knowledge and skills. In addition, there are clear policies that communicate the importance of continuous learning (Kozlowski \& Hults, 1987), and extrinsic and intrinsic rewards are provided to individuals who effectively apply newly acquired job- related knowledge (Dubin, 1990; Rosow \& Zager, 1988).

Finally, a continuous-learning work environment is characterized by an emphasis on innovation and competition, both within and outside the organizational context (Rosow \& Zager, 1988). There is a shared expectation that all organizational members strive for high levels of work performance through progressive, innovative work techniques and putting forth maximum effort. In addition, the organization as a whole is viewed as taking appropriate measures to be the best in its industry or market.

Therefore, a continuous-learning work environment is one in which organizational members share perceptions and expectations that learning is an important part of everyday work life. These perceptions and expectations constitute an organizational value or belief and are influenced by a variety of factors, including challenging jobs; 
supportive social, reward, and development systems; and an innovative and competitive work setting. In this sense, continuous learning may be considered a part of an organization's culture, as culture has been defined in terms of shared values and beliefs (Schein, 1985). These values and beliefs ultimately shape perceptions and behaviors associated with knowledge and skill acquisition and application. Thus, as transfer of training climate may be one component of an organization's overall climate, continuouslearning culture may be one component of an organization's overall culture.

This leads to an important question: What is the distinction between organizational culture and organizational climate, and how is transfer of training climate different than continuous-learning culture? Although the climate- culture distinction has yet to be fully explicated and defined, there is some literature that provides a basis for distinguishing these two constructs. For this study, we used the integration perspective of organizational culture described by Martin (1992) and James's (James \& Jones, 1974, 1976) conceptualization of climate as described earlier.

The integration perspective of organizational culture proposes that (a) culture is clear and understandable, (b) organizational members share similar perceptions about the meaning of various organizational events and activities, and (c) the relationships among various cultural manifestations (i.e., events and activities) are interpreted similarly among organizational members. This clarity, consensus, and consistency is achieved through a process of social interaction over an extended period of time, and organizational members achieve an understanding of the organizational culture in a holistic manner. That is, individuals can readily identify the specific cultural dimensions (e.g., meaning of various symbols, norms of behaviors, and shared values and 
expectations) as well as the relationships among various dimensions of culture that represent the overall organizational culture.

The first two defining characteristics of the integration perspective of organizational culture are similar to the conceptual definition offered by James and his colleagues. However, the third defining characteristic of the integration perspective suggests that cultural perceptions reflect a broader, more comprehensive representation of shared perceptions among organizational members. Organizational climate refers to the shared pattern of meanings among organizational members about specific and salient organizational elements. Organizational culture refers to the shared pattern of meaning about a comprehensive set of organizational elements. That is, cultural assumptions, values, beliefs, expectations, and behaviors are based on the interactions among a diverse set of organizational characteristics. Climate refers to shared perceptions about a more narrowly defined set of organizational elements.

Therefore, transfer of training climate refers to perceptions about characteristics of the work environment that facilitate or inhibit the use of trained skills and behaviors. It reflects the pattern of shared meaning associated with formal training programs offered by the organization. These organizational characteristics include overt managerial and peer support for training and development programs, performance appraisal systems that account for behavior and skills acquired in formal training programs, and so on.

Continuous learning is an organizationwide concern, value, belief, and expectation that general knowledge acquisition and application is important. A continuous- learning culture is reflected by a pattern of shared meanings associated with multiple methods for knowledge acquisition and application. It is based on many 
salient and observable characteristics of the work context, such as policies that emphasize employee development, as well as values and norms associated with quality work, innovation, and competitiveness. In a continuous-learning environment, organizational members support learning acquired from a variety of contexts, not just that which is gained in formal training programs. A continuous-learning culture encourages and promotes the acquisition, application, and sharing of knowledge, behaviors, and skills from a variety of sources. Continuous learning may be encouraged through supervisor and peer support for learning, diverse and challenging task assignments, and organizational systems and structures that facilitate efforts to be progressive, innovative, and competitive.

This conceptualization of continuous learning suggests that it may be one dimension of organizational culture that is related to but not identical to transfer of training climate. It is based on an organizational frame of reference, whereas climate is based on an individual frame of reference (although climate perceptions may be shared among individuals). In addition, a continuous-learning culture demonstrates the importance of the acquisition and application of new knowledge and skills gained by many means; transfer of training climate focuses on formal training activities. Yet both training climate, as operationalized by Rouiller and Goldstein (1993), and continuouslearning culture, as discussed by Noe and Ford (1992), Dubin (1990), Ro- sow and Zager (1988), and others, should encourage the application of new skills. Thus, both a transfer of training climate and a continuous-learning culture should facilitate the transfer of training. 
Hypotheses and Model

On the basis of the research and theory discussed previously, we propose five hypotheses relevant for the transfer of training. Hypothesis 1 is that there will be a direct relationship between transfer of training climate and posttraining behaviors. This hypothesis is based on the study by Rouiller and Goldstein (1993) and other research that have found a direct relationship between specific dimensions of organizational climate and behavior-related dependent variables (e.g., Kozlowski \& Hults, 1987).

Hypothesis 2 is that there will be a direct relationship between continuouslearning culture and posttraining behaviors. This hypothesis is based on the work by Ro- sow and Zager (1988), Dubin (1990), and Noe and Ford (1992), who argued that a continuous-learning work environment will impact the application of newly acquired behaviors that are gained by many means, including formal training.

Hypotheses 3 and 4 are that the transfer of training climate and continuouslearning culture will moderate the relationship between knowledge gained in training and posttraining behaviors, respectively. These hypotheses are based on the work by Mathieu, Tannenbaum, and Salas (1992), who suggested that even if learning occurs, the transfer of training climate or continuous-learning culture may not support the application of training to the job. For example, trainees may receive negative feedback from their coworkers and supervisors about the use of newly acquired skills. Alternatively, trainees may not have the time or resources necessary to use their training. 
Hypothesis 5 is that knowledge gained in training is related to posttraining behavior. This hypothesis is based on the work by Alliger and Janak (1989). Their metaanalytic review of training research found that learning was positively related to measures of posttraining behavior. If learning does not occur, the probability that trainees will demonstrate behaviors taught in training on the job will be lower than if learning does occur.

These five hypotheses are graphically represented in a transfer of training model in Figure 1. The model depicts the direct and moderating effects of climate and culture on posttraining behavior and also accounts for pretraining behavior and knowledge gained in training.

\section{Method}

Sample

This study was conducted in a private organization that owns and operates 77 supermarkets in four northeastern states. This organization employs, on average, 10 managers per store. Of these, 1 is the store manager, 1 is an assistant manager, and the remaining managers directly supervise various departments (e.g., deli, produce). Over a 5-month period, approximately 200 departmental managers were scheduled to attend a supervisory skills training program. During this time period, 159 departmental managers attended the training program. These trainees were all potential participants in this study. However, to be included in the final sample, questionnaire responses had to be received from the trainee, the trainee's supervisor, and at least 2 managerial 
coworkers. The final sample included 104 managerial trainees, 104 supervisors, and 297 coworkers; in total, 505 managers from 52 stores participated in this study. For the trainee sample, the mean age was 32 years, and $57 \%$ were women. They had been with the company an average of 8 years and had been in their current position an average of 3 years. All but two of the trainees had attended at least one previous training program offered by the organization. The peer and supervisor samples had similar demographic characteristics.

\section{Training}

One of the training programs offered by this organization is a voluntary program on basic supervisory behaviors and skills. This program was the focal point for this study. The training program consisted of 3 days of training in an off-site facility operated by the organization's training department. Training focused on interpersonal skills, such as customer and employee relations, and various administrative procedures, including shift scheduling, action planning, and purchasing. Multiple training methods were used throughout the course, including lecture, discussion and demonstration, role plays, and audiovisual techniques to facilitate both knowledge acquisition and behavior change. Although the training context was free from distractions of the work place, it did provide a context to apply newly acquired knowledge to realistic situations. For example, trainees attended a discussion and demonstration on effective interviewing techniques and then participated in a role play that provided an opportunity to practice what they learned and receive feedback on their performance. 


\section{Procedure}

Three weeks before the managers attended training, a measure of supervisory behaviors was collected from the trainee and his or her supervisor. This measure, developed from the specific objectives outlined in the training materials and interviews with the trainers, was used as a baseline to account for behaviors that had been demonstrated by trainees before training. All measures are described in more detail in a later section.

Next, the managers attended the training program. There were an average of 16 trainees per class, with 10 classes conducted over a 5-month period. Learning was assessed by using pre- and posttraining supervisory knowledge measures.

At the end of training, trainees completed a transfer of training climate and continuous-learning culture questionnaire and were asked to distribute the questionnaire to four or five managerial coworkers and their supervisor. This questionnaire included transfer of training climate items developed by Rouiller and Goldstein and continuous-learning culture items developed for our study. The questionnaires were returned directly to the researchers.

We determined that a 6- to 8-week period was needed to allow the managers time to demonstrate trained skills. Thus, approximately 6 to 8 weeks after training, each trainee and his or her supervisor completed a posttraining behavior questionnaire. This survey asked about the same behaviors as the pretraining questionnaire. As before, questionnaires were returned directly to the authors. 


\section{Insert Figure 1 Here}

Measures

Learning. As noted earlier, learning was assessed from scores on identical preand posttraining supervisory knowledge tests. The tests contained six short-answer items, which were derived from our content analysis of the training materials and then subjected to review by the trainers to ensure content validity. An example item is as follows: "Describe three barriers to the communication process." The score for each item ranged from 2 to 5 points, depending on the importance and relative time spent on the corresponding topic during training. We scored the learning measures; the maximum overall score was 20.

Pre- and posttraining behaviors. Pre- and posttraining supervisory behaviors were measured with an 18-item questionnaire based on the training materials and interviews with trainers. The items reflect a broad range of supervisory behaviors, including problem solving, decision making, communication, rewarding, and following company policies and procedures. An example item is as follows: "At the present time, the associate to be trained meets regularly with other associates to discuss problems and identify ways to solve them." The response choice format ranged from 1 never, not at all) to 5 (always, to a very great extent).

Transfer of training climate and continuous-learning culture. Transfer of training climate was assessed by using 33 items representing seven of eight scales developed by Rouiller and Goldstein (1993): goal cues, social cues, task and structural cues, positive feedback, negative feedback, punishment, and no feedback. The self-control 
scale was not applicable for the current study and was not used. All items asked respondents about training-specific characteristics of the work environment (e.g., "In your store, supervisors set goals for newly trained managers which encourage them to apply their training on the job").

Continuous-learning culture was assessed by using 24 items developed for this study. The items were developed primarily from the work by Dubin (1990), Rosow and Zager (1988), and Kozlowski and Hults (1987). We conducted group and individual interviews with corporate staff and store managers to refine and select the final set of items. The items measured perceptions, beliefs, expectations, and values that reflect a broad range of individual, task, and organizational factors that support knowledge, skill, and behavior acquisition and application (e.g., "In your store, independent and innovative thinking is encouraged by supervisors"). A list of all continuous-learning culture items are shown in the Appendix.

We should emphasize that the transfer of training climate and continuouslearning culture items differ in several ways. The climate items focus on knowledge and skill acquisition gained through formal training activities, whereas the culture items refer to knowledge and skills acquired through many means. In addition, the climate items are based on salient, observable characteristics of the work place, whereas the culture items are based on both salient characteristics and values and norms associated with less tangible aspects of the work environment. Finally, the climate items may reflect an individual-, group-, or unit-level phenomenon; the culture items, by definition, represent a shared, or aggregate-level, expectation and value about continuous learning. 


\section{Results}

\section{Reliability and Validity of Measures}

Knowledge. The mean pretraining knowledge score for all trainees was 9.71, with a standard deviation of 4.12 . The mean posttraining knowledge score for all trainees was 16.53 , with a standard deviation of 2.82. A $t$ test showed a significant difference between pre- and posttraining knowledge, $t(103)=28.86, p<.01$, indicating that the trainees knew more about basic supervisory skills and behaviors at the end of training than before training. The internal consistency estimate (Cronbach's alpha) was .80 for pretraining knowledge and .71 for posttraining knowledge.

Pre- and posttraining behaviors. To avoid concerns with self-rating bias and to decrease common-source variance, only supervisor ratings of the trainees' supervisory behaviors were used. The mean pretraining behavior score was 3.40, with a standard deviation of 0.40 . The mean posttraining behavior score was 3.90 , with a standard deviation of 0.40 . A $t$ test showed a significant difference between pre- and posttraining behaviors, $t(103)=17.60, p<.01$, indicating that the trainees displayed more of the trained skills and behaviors 6 to 8 weeks after training than 3 weeks before training.

Note that because a control group was not used, the differences between preand posttraining behaviors cannot conclusively be attributed to the training. However, the lack of a control group does not pose a problem for testing the primary hypotheses regarding the relationship between transfer of training climate and continuous- learning culture and posttraining behaviors. The pretest-posttest analysis reported in this study was simply used to demonstrate to the participating organization that after training, 
trainees possessed appropriate supervisory skills and knowledge. Sackett and Mullen (1993) argued that a pretest-posttest research design is appropriate when it is important to assess whether a specific knowledge, skill, or ability level has been achieved, or when it is necessary to document individual performance, as was the case for this study.

The internal consistency estimates for the pre- and posttraining behavior measures were adequate. Cronbach's alpha was .89 for pretraining scores and .93 for posttraining scores.

Climate and culture. The transfer of training climate and continuous-learning culture items were factor analyzed to assess the dimensionality of the measures. The results from a principal components solution using a varimax rotation yielded an interpretable nine-factor solution that accounted for $68.3 \%$ of the variance. Factor loadings of .40 or higher were used to select items to describe a factor. The factors included six transfer of training climate scales (social and goal cues, task cues, nofeedback consequences, negative reinforcement consequences, extrinsic reinforcement consequences, and intrinsic reinforcement consequences) and three continuouslearning culture scales (social support, continuous improvement, and continuous competitiveness). Factor definitions and sample items are shown in Table 1.

Note that the climate scales generated from this analysis are similar but not identical to those proposed by Rouiller and Goldstein (1993). This finding may be due to differences in the methods used to derive the scales. Rouiller and Goldstein derived their scales through expert sorting judgments, whereas we used factor analytic techniques. 
Levels of Aggregation

Determining the appropriate level of aggregation represents one of the most important aspects of analyzing the climate and culture data. According to Joyce and Slocum (1984), there are at least three methodological criteria that can be used to evaluate the appropriate aggregation level of climate and culture scores: (a) discrimination, or demonstrable differences between mean perceptions of climate at different levels of aggregation; (b) consensus, or agreement in perceptions within levels of aggregation; and (c) predictable relationships to organizational or individual criteria.

Three levels of aggregation were considered: individual, group, and store. The individual level of aggregation is based on individual scores for the climate and culture dimensions. The group level of aggregation is based on an average score for the group of individuals selected by the trainees to provide climate and culture data. These selfselected subgroups (SSSGs) include the trainee, at least two of his or her managerial coworkers, and his or her direct supervisor. The store level of aggregation is based on the average climate and culture scores from all individuals providing information about a particular store.

Discrimination. To evaluate whether the group or store levels of aggregation contributed to the variance in climate and culture scores, we conducted a series of analyses of variance (ANOVAs). The independent variables were the group and store levels of aggregation. The dependent variables were the transfer of training climate and continuous-learning culture scales. 
The results from these analyses showed that both the group and store levels of aggregation contributed to differences across all of the climate and culture dimensions. All $F$ values were significant at $p<.01$. This suggests that with regard to discrimination, either of these two levels may be the appropriate level of aggregation.

Consensus. James, Demaree, and Wolf (1984) developed an index of withingroup interrater agreement, $r_{w g(j)}$, which can be used to assess the extent to which individuals share perceptions about transfer of training climate and continuous-learning culture. This index is interpreted the same as the Pearson product-moment correlation. The index is appropriate for multiple items that are parallel indicators of a construct when raters are judging the same target. James et al. (1984) showed that other common estimators of interrater agreement, such as the intraclass correlation, are severely attenuated when there is restriction of range on item responses, which occurs when agreement among raters is high. The multiple-item estimator $r_{w g(j)}$ was computed for all of the climate and culture scales across SSSGs $(N=104)$ and stores $(N=52)$.

The results showed that the average within-group interrater agreement was higher for SSSGs than for stores across all of the transfer of training climate and continuous- learning culture dimensions. For the SSSG level of aggregation, the average within-group interrater agreement was 0.83 across the climate dimensions, and 0.88 across the culture dimensions. For the store level of aggregation, the average within-group interrater agreement was 0.60 across the climate dimensions, and 0.67 across the culture dimensions. 
Predictability. To assess the relative predictability of the transfer of training climate and continuous-learning culture scales for the individual, group, and unit levels of aggregation, nine separate hierarchical multiple regression analyses were conducted—one regression analysis for each of the climate and culture scales. These analyses were based on the notion that individual-, group-, and store-level climate and culture scores can independently account for unique variance in posttraining behaviors.

This analytic technique, known as a contextual effects analysis, uses models of the general form:

$$
Y=a+b_{1} x+b_{2} x+e,
$$

where $x$ refers to the group mean on $x$. This general model can be used to identify aggregate-level effects on a particular dependent variable. For a more detailed discussion of this approach, see Iverson (1991).

Supervisor ratings of posttraining behavior were used as the dependent variable. Supervisor ratings of pretraining behavior were entered as Step 1 in the hierarchical multiple regression to account for pretraining differences across the trainees. Pretraining supervisory knowledge was entered as Step 2, and posttraining knowledge was entered as Step 3.

For Step 4 in the regression analyses, the individual- level climate and culture score for a particular dimension was entered. In only four of the analyses, the individuallevel climate and culture scores explained additional variance (from 1.6\% to $2.6 \%$ ) in posttraining behaviors beyond that accounted for by pretraining behaviors and knowledge scores. SSSG scores for each of the culture and climate scales were 
entered in Step 5 of the regression analyses. In all of the analyses, the group-level climate and culture scores explained additional variance in posttraining behaviors beyond that accounted for by pretraining behaviors and knowledge. The change in $R^{2}$ was significant in each analysis, and the additional variance that was explained ranged from $5.6 \%$ to $13.2 \%$.

Finally, store-level climate and culture scores were entered in Step 6 of the regression analysis. In all analyses, the store-level scores did not explain any additional variance in posttraining behavior scores. Similar results were found when the pretraining behavior and knowledge scores were not included in the analyses.

Based on the discrimination, consensus, and predictability criteria, the SSSG appears to be the most appropriate level of aggregation for all of the transfer of training climate and continuous-learning culture dimensions. All remaining analyses were conducted by using group-level data.

\section{Insert Table 2 Here}

\section{Factor Structure of Climate and Culture}

Table 2 shows the means, standard deviations, and correlations among the knowledge, behavior, and SSSG-level culture and climate scales. The correlations among climate and culture scales were moderate to high. Correlations among the climate scales ranged from .46 to .70 (mean correlation $=.57$ ). Correlations among the culture scales ranged from .38 to .67 (mean correlation $=.54$ ). In addition, the 
correlations between the climate and culture scales were also moderate to high, ranging from .29 to .78 (mean correlation $=.52)$.

Although the exploratory factor analysis showed support for multiple dimensions of climate and culture, the high cross-dimension correlations suggested that transfer of training climate and continuous-learning culture may be better represented by fewer than nine factors.

To test whether a simpler structure exists, we conducted a confirmatory factor analysis using LISREL VII (Jöreskog \& Sörbom, 1989). This analysis tested a twofactor model, with the six transfer of training scales representing a single underlying climate construct, and the three continuous-learning culture scales representing a single underlying culture construct. The fit of this model was evaluated by using the sample variance-covariance matrix as input and a maximum likelihood solution. The overall chisquare test was statistically nonsignificant, $X^{2}(26, N=104)=23.83, p>.05$. The goodness-of-fit index was 0.96 , and the root mean square residual for the predicted minus observed correlation matrices was 0.02 . Thus, a two-factor solution of transfer of training climate and continuous-learning culture was supported.

Insert Figure 2 Here

\section{LISREL Analysis of the Transfer of Training Model}

To test the hypotheses and the transfer of training model, a series of structural equations analyses were conducted by using LISREL VII (Jöreskog \& Sörbom, 1989). 
First, a measurement model with single indicators of climate and culture was used to test Hypotheses 1, 2, and 5. Next, measurement models with interaction terms were examined to test Hypotheses 3 and 4. Finally, a structural model using multiple indicators of climate and culture was examined to determine which of the climate and culture scales were the strongest indicators of the underlying constructs in the overall model. The fit of all models was evaluated by using the sample variance-covariance matrix as input and a maximum likelihood solution.

For the measurement model without interaction terms, the overall chi-square was statistically nonsignificant, $X^{2}(4, N=104)=6.72, p>.05$, suggesting good model fit. The goodness-of-fit index was 0.98 , and the root mean square residual for the predicted minus observed correlation matrices was 0.04 , also suggesting good model fit. All standardized path coefficients were significant except for the path between posttraining knowledge and posttraining behaviors. The residuals for each of the observed measures were low, suggesting that the measures represent reasonable indicators of the constructs in question. The results, which fully support Hypotheses 1 and 2, are displayed in Figure 2.

The significance of the interaction terms was tested by comparing the chi-square values of measurement models including and excluding the product terms (cf. Mathieu et al., 1992). The results showed that the models that included the interaction terms (i.e., climate-posttraining knowledge and culture-posttraining knowledge, separately and simultaneously) did not yield significantly better fits. Therefore, Hypotheses 3 and 4 were not supported. 
To examine which of the climate and culture factors were the strongest indicators in the overall model, a structural equations analysis of the transfer of training model was tested using multiple indicators of transfer of training climate and continuous-learning culture. The overall chi- square for the multiple-indicator model was statistically nonsignificant, $\quad X^{2}(61, N=104)=50.83, p>.05$, suggesting good model fit. The goodness-of-fit index was 0.93 , and the root mean square residual for the predicted minus observed correlation matrices was 0.03 , also suggesting good model fit.

It should be noted that given the results from the confirmatory factor analysis reported previously, the importance of the path coefficients derived from this analysis should be considered exploratory in nature. For transfer of training climate, the social and goal cues indicator had the highest path coefficient $(0.90, p<.01)$. The remaining path coefficients for the climate indicators ranged from 0.65 to 0.77 (all significant at $p<.01)$. For continuous-learning culture, the social support indicator had the highest path coefficient $(0.91, p<.01)$. The remaining path coefficients for the culture indicators ranged from 0.62 to 0.74 (all significant at $p<.01$ ).

\section{Discussion}

The main purpose of this study was to examine the influence of two specific dimensions of organizational climate and culture on the transfer of supervisory behaviors learned in a formal training program. Two of the five hypotheses were fully 
supported: Both transfer of training climate and continuous-learning culture had direct effects on posttraining behaviors.

This study extended Rouiller and Goldstein's (1993) study in several ways. First, we empirically examined and determined the appropriate level of aggregation for both training climate and continuous-learning culture. Second, we demonstrated that climate and culture influenced the application of trained skills among experienced employees. In conducting this analysis, we included a pretraining measure of supervisory behavior to account for behavioral differences before training. Third, an additional dimension of the work environment, continuous-learning culture, was shown to be positively related to posttraining behaviors.

The results support the view that the work environment is important for the application of newly acquired behavior and skills. Similar to Rouiller and Goldstein (1993), we found that the transfer of training climate had a direct impact on posttraining behaviors. On the basis of both studies, we conclude that various training-related cues in the work environment can facilitate or hinder the application of newly trained behaviors for both new and experienced supervisors. In addition, we found that other salient characteristics of the work environment, not directly related to training but more generally related to learning, also had a direct effect on the transfer of training.

\section{Learning Culture}

Behaviors that send a message that learning is important and valued, and cues that suggest the organization is innovative and competitive, appear to encourage the 
application of newly trained behaviors. This is particularly interesting because it shows that a continuous-learning culture can influence specific behaviors associated with a particular training program.

The values associated with continuous learning are embodied in many of the prevalent approaches to organizational change, such as total quality management (e.g., Juran \& Gyma, 1993), and are advocated in many recent books on business organizations (e.g., Kanter, 1989). Proponents of continuous learning have suggested that a learning-oriented culture can have a broad influence on employee growth and organizational effectiveness, but this is the first study to show a relationship between learning culture and specific posttraining behaviors. Moreover, because learningoriented signals are not associated with a specific training course, they may have an effect across a wide range of courses, although that remains to be tested in future research.

\section{Implications for Practice}

The results of this study have implications for enhancing training effectiveness.

The support for Hypotheses 1 and 2 confirms the influence of the work environment on the transfer of training. Thus, it is essential that organizations examine their work environment to determine whether changes may be required. Diagnostic work could be based on surveys, focus groups, or interviews and should probably include an assessment of learning-related as well as training-related cues and signals. Then, targeted interventions could be designed to remove obstacles and encourage transfer. For example, incorporating discussions and skill-building exercises on how to overcome 
barriers to transfer may certainly facilitate the application of trained skills and behaviors to the work setting. The research on relapse prevention in formal training activities by Marx (1982) and Gist (1991) supports this course of action. In addition, interventions associated with organizational development activities, such as survey feedback about the organization's culture and climate, may also be used to change the work environment to facilitate training transfer.

Each of the six climate scales contributed significantly to the underlying climate construct. Similar results were found for the three culture scales and the underlying culture construct. However, for both training climate and learning culture, the scale that exhibited the highest path coefficient was the one most closely related to the social support system ( 0.90 and 0.91 , respectively). These findings are consistent with sociotechnical theory (e.g., Purser and Pasmore, 1992; Thompson, 1967) and highlight the central role of social factors in establishing supportive training and learning environments. One example of social support is when supervisors or peers meet with newly trained managers to discuss how they can apply what they are learning in training on the job. Social support can also be expressed when supervisors encourage independent and innovative thinking among their employees. The former is an indicator of a positive training climate; the latter, an indicator of a positive learning culture.

Moreover, the level of aggregation analyses showed that, at least in this sample, training climate and learning culture tend to exist at the self-selected work group level. That is, people who commonly interact with each other at work are most likely to share perceptions of the work environment. This finding, in conjunction with those noted previously, suggests that interventions that target supervisors, coworkers, and other 
people who interact with trainees may yield the greatest dividends toward establishing a supportive training and learning environment (e.g., Baldwin \& Magjuka, 1991).

\section{Future Research}

Given the recent findings regarding contextual influences on training effectiveness, future studies should continue to examine the role of the work environment. Future work should examine how the work environment influences trainee perceptions and behavior. For example, do culture and climate affect individual behavior by influencing self-efficacy (Gist, 1987), motivation (Noe, 1986), or expectations about formal and informal training experiences (Tannenbaum, Mathieu, Salas, \& CannonBowers, 1991)? If culture and climate do have a direct effect on self-efficacy and motivation to learn, then trainees in a less supportive work environment will be less likely to acquire new knowledge gained from any means, formal training programs or otherwise.

Another thrust for future research is to incorporate the literature on organizational learning into the conceptual and operational frameworks that have been used to demonstrate the importance of the work environment for the transfer of training. Learning organizations possess multiple characteristics that provide an extremely receptive setting for many kinds of developmental activities, including those directed at the individual and organizational level (e.g., Fiol \& Lyons, 1985; Huber, 1991; Leavitt \& March, 1988). For example, Lundberg (in press) suggests that the nature of an organization's culture is extremely important for organizational learning. Without an appropriate culture, there is no repository for learning. Thus, additional research is 
required to explore the relationships among organizational learning, an organization's continuous-learning culture, and effective training and development activities.

\section{Limitations}

Some limitations of this study should be noted. The study did not include a control group, so firm conclusions regarding learning and behavior change as a result of training cannot be made. In addition, the lack of a significant relationship between training knowledge and posttraining behavior was surprising. However, a close examination of Alliger and Janak's (1989) review showed that half of the reported correlations between learning and behavior were \pm 0.06 or less. Thus, it is not uncommon for knowledge and behavior to be uncorrelated.

One possible explanation for the result in this study is that the two measures assessed distinct outcomes of training. Although the behavioral and knowledge measures were both based on course content, no attempt was made to ensure that they overlapped in content. For example, the test item that asked trainees to identify obstacles to communication did not have a corresponding item in the behavioral measure. Although both measures were related to course content, the knowledge items focused on different aspects of the criterion space than the behavioral items. Moreover, from a pragmatic perspective, using two content-valid but nonredundant measures of training effectiveness is probably more valuable to an organization than using fully parallel knowledge and behavior measures. 
This study demonstrated that the work environment, defined in terms of training climate and learning culture, is directly related to the transfer of trained behaviors. It was, to the best of our knowledge, the first study to show that continuous-learning culture is related to the application of behaviors gained from a specific training course. In particular, the social support system was shown to play a central role in facilitating the transfer of training. Future research that pursues this line of inquiry is necessary if we are to go beyond the question of whether training works to the more important question of why training works. 


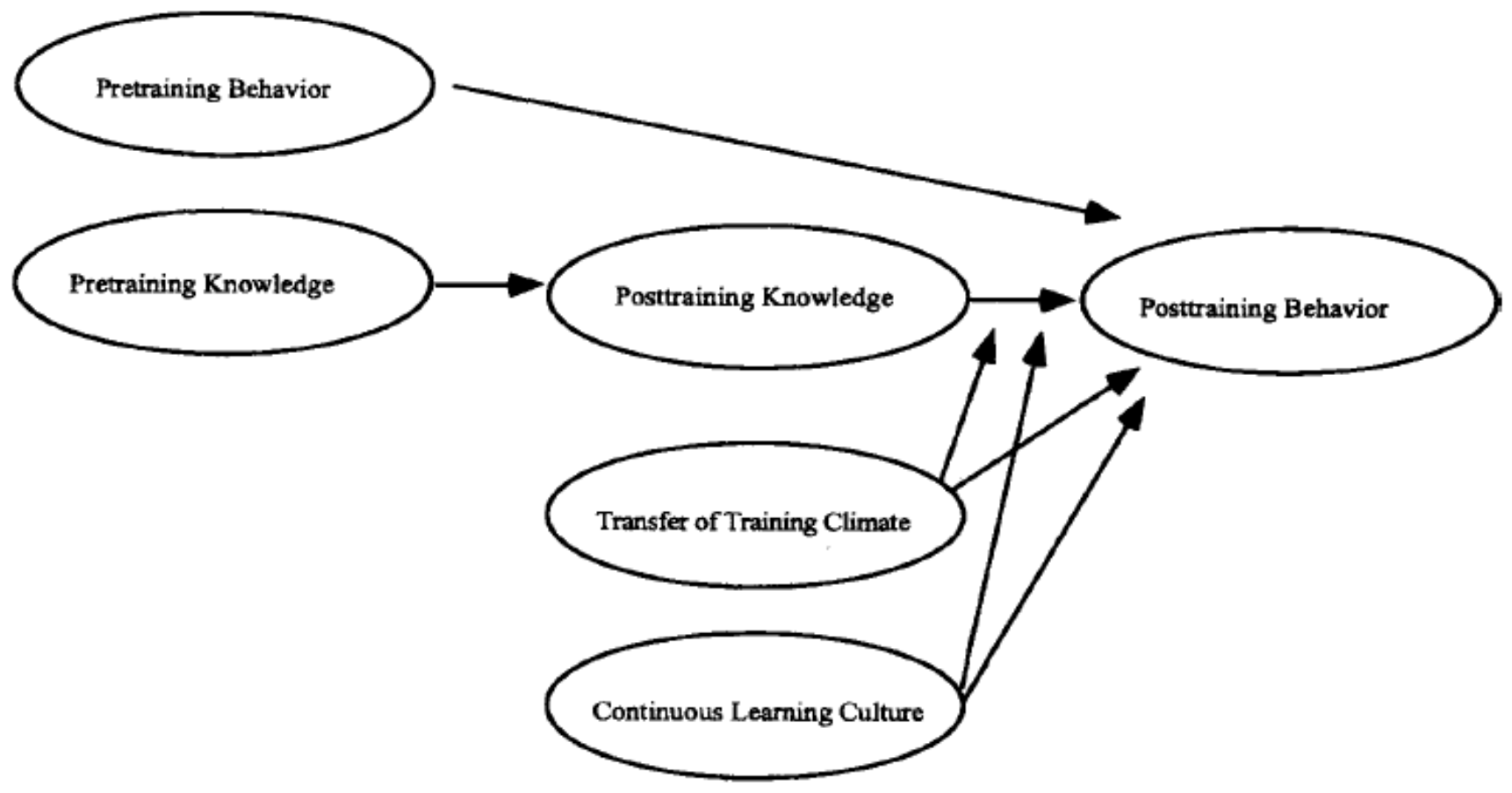

Figure 1. Model of transfer training. 
Table 1. Definitions and example items for transfer of training climate and continuous learning culture scales.

Transfer of training climate

Social and goal cues: The extent to which supervisors and coworkers encourage and set goals for trainees to use new skills and behaviors acquired in training.

Task cues: The extent to which characteristics of a trainee's job prompt or remind him or her to use new skills and behaviors acquired in training.

No-feedback consequences: The extent to which supervisors neither support nor discourage the application of new skills and behaviors acquired in training.

Punishment consequences: The extent to which trainees are openly discouraged from using new skills and behaviors acquired in training.

Extrinsic reinforcement consequences: The extent to which trainees receive extrinsic rewards for using new trained skills and behaviors acquired in training.

Intrinsic reinforcement consequences: The extent to which trainees receive intrinsic rewards for using newly trained skills and behaviors acquired in training.
In this store, newly trained managers discuss how to apply their training on the job with their supervisors and other managers.

In this store, the job of a newly trained manager is designed in such a way as to allow them to use the skills taught in training.

In this store, supervisors do not notice newly trained managers who use their training.

In this store, when newly trained managers fail to use their training, they can expect to be reprimanded.

In this store, newly trained managers who successfully use their training will receive a salary increase.

In this store, supervisors and other managers appreciate newly trained managers who perform their job as taught in training.

\section{Continuous-learning culture}

Social support: The extent to which supervisors and coworkers encourage the acquisition and use of any new relevant skills and behaviors.

Continuous innovation: The extent to which an organization promotes ongoing efforts to be innovative and progressive.

Competitiveness: The extent to which an organization promotes an image of being the best in its field through high levels of individual performance.
In this store, coworkers encourage each other to use new knowledge and skills on the job.

This corporation expects continuing technical excellence and competence.

This corporation attempts to be better than its competition.

Note. For all items, response choices ranged from 1 (strongly disagree) to 5 (strongly agree). 
Table 2. Means, standard deviations, and correlations among transfer of training climate and continuous learning culture scales.

\begin{tabular}{|c|c|c|c|c|c|c|c|c|c|c|c|c|c|c|c|}
\hline Stole & $M$ & $S D$ & 1 & 2 & 3 & 4 & 5 & 6 & 7 & 8 & 9 & 10 & 11 & 12 & 13 \\
\hline 1. Postirainingknowledge & 16.53 & 282 & - & & & & & & & & & & & & \\
\hline 2. Postitrainingbutravior & 390 & 0.40 & .09 & - & & & & & & & & & & & \\
\hline 3. Pretraining binoulatge & 971 & 4.12 & .82 & 23 & - & & & & & & & & & & \\
\hline 4. Pretraining hehavior & 3.40 & 0.40 & 07 & .31 & 20 & $=$ & & & & & & & & & \\
\hline 5. Socinl and pal cues & 3.33 & 0.95 & 10 & .47 & 09 & .20 & $=$ & & & & & & & & \\
\hline 6. No-bedback conscquenos & 329 & 0.86 & 05 & 39 & 04 & 19 & .70 & $=$ & & & & & & & \\
\hline 7. Nepalve reidorceroend consquences & 3.34 & 0.74 & 18 & .45 & 13 & 24 & 69 & 62 & - & & & & & & \\
\hline 3. Exinisic reinforcement consoquences & 3.54 & 1.07 & 14 & 38 & 13 & 16 & 61 & .54 & 53 & - & & & & & \\
\hline 9. Intri set reidortement sonstutences & 2.63 & 0.99 & 18 & 36 & .17 & 16 & .56 & 50 & 51 & .55 & - & & & & \\
\hline I0. Task bues & 3.22 & D_B6 & 03 & .33 & 03 & 15 & .64 & 53 & 39 & 48 & .45 & $=$ & & & \\
\hline 11. Social suppot & 3,31 & 0.91 & $\Delta 7$ & .48 & .06 & 23 & $.7 \mathrm{~B}$ & .65 & 70 & 61 & 55 & .97 & - & & \\
\hline 12. Conthnuousinnowation & 4.14 & 072 & 06 & .43 & .05 & 21 & .62 & 53 & 47 & 47 & 41 & 4 & 67 & - & \\
\hline 13. Competitiveness & 4.57 & 0.55 & 11 & 41 & .11 & .18 & .52 & 38 & -41 & .29 & .41 & .18 & .54 & 58 & - \\
\hline
\end{tabular}

Note: All correlations $>.21$ are significant at $p<.01$. 


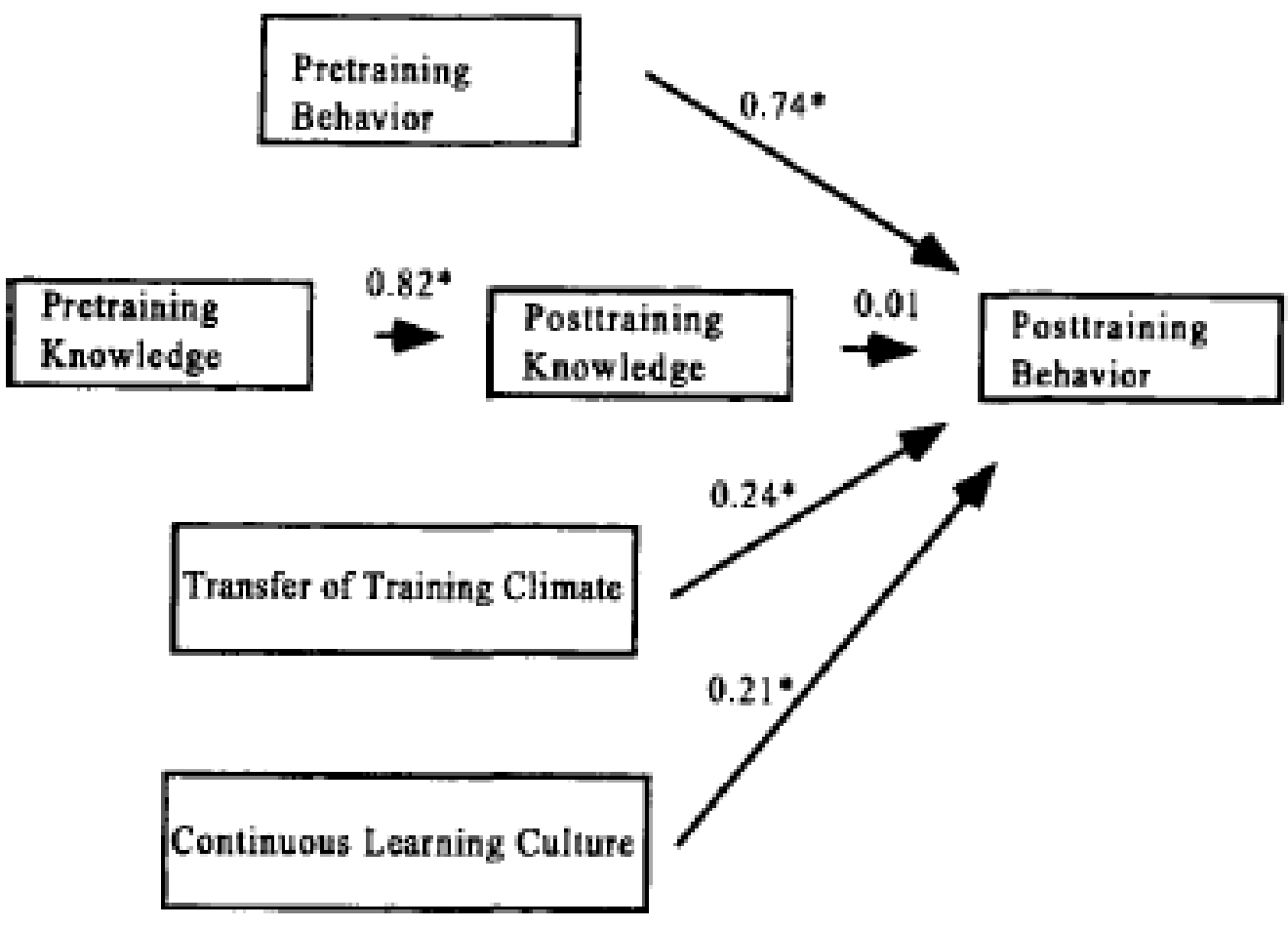

Figure 2. Measurement model. Only standardized path co-efficients are displayed. * $p<.01$ 


\section{References}

Alliger, G. M., \& Janak, E. A. (1989). Kirkpatrick's levels of training criteria: Thirty years later. Personnel Psychology, 42, 331-342.

Baldwin, T. T, \& Ford, J. K. (1988). Transfer of training: A review and directions for future research. Personnel Psychology, 41, 63-105.

Baldwin, T. T., \& Magjuka, R. J. (1991). Organizational training and signals of importance: Linking pretraining perceptions to intentions to transfer. Human Resource Development Quarterly, 2, 25-36.

Campbell, J. P. (1988). Training design for performance improvement. In J. P. Campbell \& R. J. Campbell (Eds.), Productivity in organizations (pp. 177-215). San Francisco, CA: Jossey-Bass.

Dubin, S. S. (1990). Maintaining competence through updating. In S. L. Willis \& S. S. Dubin (Eds.), Maintaining professional competence \{pp. 9-43). San Francisco: Jossey-Bass.

Fiol, C. M., \& Lyons, M. A. (1985). Organizational learning. Academy of Management Review, 10, 803-813.

Ford, J. K., Quinones, M. A., Sego, D. J., \& Sorra, J. S. (1992). Factors affecting the opportunity to perform trained tasks on the job. Personnel Psychology, 45, 511527.

Gist, M. E. (1987). Self-efficacy: Implications for organizational behavior and human resource management. Academy of Management Review, 12, 472-485. 
Gist, M. E. (1991). Effects of self-efficacy and post-training intervention on the acquisition and maintenance of complex interpersonal skills. Personnel Psychology, 44, 837-861.

Hellreigel, D., \& Slocum, J. W., Jr. (1974). Organizational climate: Measures, research, and contingencies. Academy of Management Journal, 17, 255-280.

Huber, G. P. (1991). Organizational learning: The contributing processes and the literatures. Organization Science, 2, 88115.

Iverson, G. R. (1991). Contextual analysis. Newbury Park, CA: Sage.

James, L. R., Demaree, R. G., \& Wolf, G. (1984). Estimating within-group interrater reliability with and without response bias. Journal of Applied Psychology, 69, 8598.

James, L. R., James, L. A., \& Ashe, D. K. (1990). The meaning of organizations: The role of cognition and values. In B. Schneider (Ed.), Organizational climate and culture (pp. 4084). San Francisco, CA: Jossey-Bass.

James, L. R., \& Jones, A. P. (1974). Organizational climate: A review of theory and research. Psychologal Bulletin, 81, 1096-1112.

James, L. R., \& Jones, A. P. (1976). Organizational structure: A review of structural dimensions and their conceptual relationship with individual attitudes and behavior. Organizational Behavior and Human Performance, 16, 74-113.

Jöreskog, K., \&Sörbom, D. (1989). LISREL VII. Mooresville, IN: Scientific Software. Joyce, W. E, \& Slocum, J. W. (1984). Collective climate: Agreement as a basis for defining aggregate climates in organizations. Academy of Management Journal, 27, 721-742. 
Juran, J. M., \& Gyrna, F. M. (1993). Quality planning and analysis. New York: McGrawHill.

Kanter, R. M. (1989). When giants learn to dance. New York: Simon \& Schuster.

Kirkpatrick, D. L. (1967). Evaluation of training. In R. L. Craig \& L. R. Bittel (Eds.), Training and development handbook (pp. 87-112). New York: McGraw-Hill.

Kozlowski, S. W. J., \& Hults, B. M. (1987). An exploration of climates for technical updating and performance. Personnel Psychology, 40, 539-563.

Leavitt, B., \& March, J. G. (1988). Organizational learning. Annual Review of Sociology, 14, 319-340.

Lundberg, C. C. (in press). Learning in and by organizations: Three conceptual issues. International Journal of Organizational Analysis, 3.

Luthans, F., \& Kreitner, R. (1985). Organizational behavior modification and beyond. Glenview, IL: Scott, Foresman.

Martin, J. (1992). Cultures in organizations: Three perspectives. New York: Oxford University Press.

Marx, R. B. (1982). Relapse prevention for managerial training: A model for maintenance of behavior change. Academy of Management Review, 7, 433-441.

Mathieu, J. E., Tannenbaum, S. L, \& Salas, E. (1992). Influences of individual and situational characteristics on measures of training effectiveness. Academy of Management Journal, 35, 828-847.

Noe, R. A. (1986). Trainees' attributes and attitudes: Neglected influences on training effectiveness. Academy of Management Review, 11, 736-749. 
Noe, R. A., \& Ford, J. K. (1992). Emerging issues and new directions for training research. In G. R. Ferris \& K. M. Rowland (Eds.), Research in personnel and human resource management (Vol. 10, pp. 345-384). Greenwich, CT: JAI Press.

Pentland, B. T. (1989, August). The learning curve and the forgetting curve: The importance of time and timing in the implementation of technological innovations. Paper presented at the 49th annual meeting of the Academy of Management, Washington, DC.

Pritchard, R. D., \& Karasick, B. W. (1973). The effect of organizational climate on managerial job performance and job satisfaction. Organizational Behavior and Human Performance, 9, 126-146.

Purser, R. E., \& Pasmore, W. A. (1992). Organizing for learning. Research in Organizational Change and Development, 6, 37-114.

Rosow, J. M., \& Zager, R. (1988). Training: The competitive edge. San Francisco, CA: Jossey-Bass.

Rouiller, J. Z., \& Goldstein, I. L. (1993). The relationship between organizational transfer climate and positive transfer of training. Human Resource Development Quarterly, 4, 377390.

Saari, L. M., Johnson, T. R., McLaughlin, S. D., \& Zimmerte, D. M. (1988). A survey of management training and education practices in U.S. companies. Personnel Psychology, 41, 731-743.

Sackett, P. R., \& Mullen, E. J. (1993). Beyond formal experimental design: Towards an expanded view of the training evaluation process. Personnel Psychology, 46, 613-627. 
Schein, E. H. (1985). Organizational culture and leadership: A dynamic review. San Francisco: Jossey-Bass.

Schneider, B. (1983a). Interactional psychology and organizational behavior. In L. L. Cummings \& B. Staw (Eds.), Research in organizational behavior (Vol. 5, pp. 131). Greenwich, CT: JAI Press.

Schneider, B. (1983b). Work climates: An interactionist perspective. In N. W. Feimer \& E. S. Geller (Eds.), Environmental psychology: Directions and perspectives (pp. 153-178). New York: Praeger.

Schneider, B. (1985). Organizational behavior. Annual Review of Psychology, 36, 573611.

Schneider, B. (1990). Organizational climate and culture. San Francisco, CA: JosseyBass.

Tannenbaum, S. L, Mathieu, J. E., Salas, E., \& Cannon-Bowers, J. A. (1991). Meeting trainees' expectations: The influence of training fulfillment on the development of commitment, self-efficacy, and motivation. Journal of Applied Psychology, 76, 765-769.

Tannenbaum, S. I., \& Yukl, G. A. (1992). Training and development in work organizations. Annual Review of Psychology, 43, 399-441.

Thompson, J. D. (1967). Organizations in action. New York: McGraw-Hill.

Wexley, K. R., \& Latham, G. P. (1991). Developing and training human resources in organizations. New York: Harper Collins.

Zohar, D. (1980). Safety climate in industrial organizations: Theoretical and applied implications. Journal of Applied Psychology, 65, 96-102. 